\title{
Keanekaragaman Lamun di Pantai Kora-Kora, Kecamatan Lembean Timur Kabupaten Minahasa Sulawesi Utara (The Diversity of Seagrass in Kora-kora Beach, East Lembean District, Minahasa Regency, North Sulawesi Province)
}

\author{
Yuniarti Yurike Wondal(1)*, Sendy Rondonuw( ${ }^{1)}$, Pience V. Maabuat ${ }^{1)}$ \\ 1)Program Studi Biologi, Jurusan Biologi FMIPA UNSRAT Manado, 95115 \\ *Email korespondensi: yuniwondal24@gmail.com
}

Diterima 5 Agustus 2017, diterima untuk dipublikasikan 31 Agustus 2017

\begin{abstract}
Abstrak
Penelitian dilakukan di Pantai Kora-Kora, Kecamatan Lembean Timur, Kabupaten Minahasa, Provinsi Sulawesi Utara dari Mei hingga Juni 2017. Penelitian bertujuan untuk menganalisis keanekaragaman lamun di Pantai Kora-Kora. Penelitian menggunakan metode purposive random sampling untuk menentukan lokasi penelitian. Hasil penelitian menunjukan bahwa di Pantai Kora-Kora, Kecamatan Lembean Timur ditemukan enam (6) jenis lamun yang termasuk dalam dua (2) suku yaitu Hidrocharitaceae meliputi Enhallus acoroides, Thallasia hemprichii, dan Halodule uninervis dan Cymodoceaceae yaitu Cydomocea rotundata, C. serrulata dan Syringodium isoetifolium. Jenis-jenis tersebut ialah lamun yang tersebar di pesisir tropis Indo-Pasifik. Jenis yang berperan penting berdasarkan INP di Stasiun I, II dan III berturut-turut yaitu $\mathrm{E}$. acoroides $(58,50 \%), \mathrm{H}$. uninervis $(58,60 \%)$ dan $\mathrm{S}$. isoetifolium (63,0\%). Indeks keanekaragaman jenis lamun di lokasi penelitian di Panta Kora-kora termasuk sedang $\left(H^{\prime}: 1,71\right)$.

Kata kunci: Pantai Kora-Kora, keanekaragaman lamun.
\end{abstract}

\begin{abstract}
The research was conducted in the Kora-Kora Beach, East Lembean District, Minahasa Regency, North Sulawesi Province from May to June 2017. The aim of study was to analyze the diversity of seagrass on Kora-Kora Beach. The purposive random sampling method was used in this research to determine the research locations. The results showed that Kora-Kora Beach had six (6) seagrass species that were included in two (2) families namely Hidrocharitaceae (Enhallus acoroides, Thallasia hemprichii, Halodule uninervis) and Cymodoceaceae (Cydomocea. rotundata, C. serrulata and Syringodium isoetifolium). These seagrass species were found in the tropical IndoPacific coastlines. The important species based on Importance Value Index in Station I, II and III were E. acoroides (58.50\%), H. uninervis (58.60\%) and S. isoetifolium (63.0\%), respectively. The seagrass species diversity index in the study areas in the Kora-kora Beach was moderate ( $H$ ': 1.71).

Keywords: Kora-Kora Beach, seagrass diversity.
\end{abstract}




\section{PENDAHULUAN}

Sulawesi Utara merupakan salah satu provinsi di Indonesia yang memiliki wilayah perairan laut yang kaya akan sumber daya hayati salah satu diantaranya yaitu lamun (seagrass). Keberadaan lamun di perairan sangat penting mengingat fungsi lamun sebagai sumber produktivitas primer di ekosistem pantai dan tempat hidup berbagai biota di laut.Ekosistem padang lamun tersebut berasosiasi dengan berbagai jenis biota laut yang bernilai sangat penting dengan tingkat keragamannya yang tinggi (Nainggolan 2011).

Lamun di Indonesia ada 13 jenis yang telah teridentifikasi (Kiswara 1999 dalam Susetiono 2004). Jenisjenis lamun yang telah diteliti di Sulawesi Utara yaitu di Semenanjung Minahasa sebanyak 7 jenis (Peuru 2005), perairan Tanjung Merah Bitung 7 jenis (Takendengan, 2007), pesisir Desa Lihunu 7 jenis (Zakiah 2015) dan di pesisir Molas, Meras, Bahowo sebanyak 5 jenis (Maabuat 2011). Keanekaragaman lamun di Pantai Kora-kora Kecamatan Lembean Timur belum pernah dilaporkan. Aktivitas masyarakat yang cukup tinggi serta keberadaan pemukiman penduduk yang dekat dengan pesisir dapat mempengaruhi keanekaragaman lamun. Fungsi ekologis dan manfaat lamun yang penting tetapi ancaman yang tinggi membutuhkan penelitian sebagai data base tentang keanekaragaman lamun agar kelestarian lamun dapat terus terjaga dalam rangka konservasi sumber daya hayati laut di Sulawesi Utara. Penelitian bertujuan untuk menganalisis keanekaragaman lamun di Pantai Kora-Kora.

\section{METODE}

Penelitian dilakukan pada Mei 2017 - Juni 2017 pada saat surut terendah. Lokasi penelitian dibagi menjadi tiga stasiun yaitu Stasiun I berada dekat pemukiman warga, Stasiun II di dekat bekas dermaga dan Stasiun III letaknya dekat dengan hutan (Gambar 1).

\section{Identifikasi dan Pengambilan Sampel}

Metode yang digunakan dalam penelitian ini ialah purposive random sampling, yaitu dengan membuat garis transek dan plot kuadrat $1 \times 1 \mathrm{~m}^{2}$ dan sebanyak tiga (3) stasiun ditentukan di lokasi penelitian. Jarak antar stasiun sekitar $100 \mathrm{~m}$. Setiap stasiun dibagi menjadi tiga (3) garis transek. Jarak antar garis transek ialah $10 \mathrm{~m}$ dan panjang tiap garis transek ialah $100 \mathrm{~m}$. Setiap garis transek dibuat 10 plot dan jarak antar plot sekitar $10 \mathrm{~m}$. Total plot penelitian berjumlah 30 plot untuk tiap stasiun. Total seluruh transek pada lokasi ialah sembilan garis transek. Total plot penelitian berjumlah 90 plot. Sampel tiap jenis lamun dibawa ke Laboratorium Ekologi, Jurusan Biologi

Fakultas Matematika dan IImu Pengetahuan Alam, Universitas Sam Ratulangi. Jenis lamun yang ditemukan diidentifikasi berdasarkan karakteristik morfologi (Azkab 2009, Susetiono 2004).

\section{Analisis Data}

Analisis data mencakup Kerapatan Jenis $(\mathrm{K})$ dan Indeks Nilai Penting (INP). Keanekaragaman lamun diketahui berdasarkan Indeks keanekaragaman $\left(\mathrm{H}^{\prime}\right)$ menurut Shannon-Wienner (Magurran, 1991). Keanekaragaman dikelompokkan menjadi tiga (3) tingkat keanekaragaman $\left(H^{\prime}\right)$ sebagai berikut: $H^{\prime} \geq 3$ : tinggi; $H^{\prime}=1 \leq H^{\prime} \leq 3$ : sedang; $H^{\prime} \leq 1$ : rendah. 


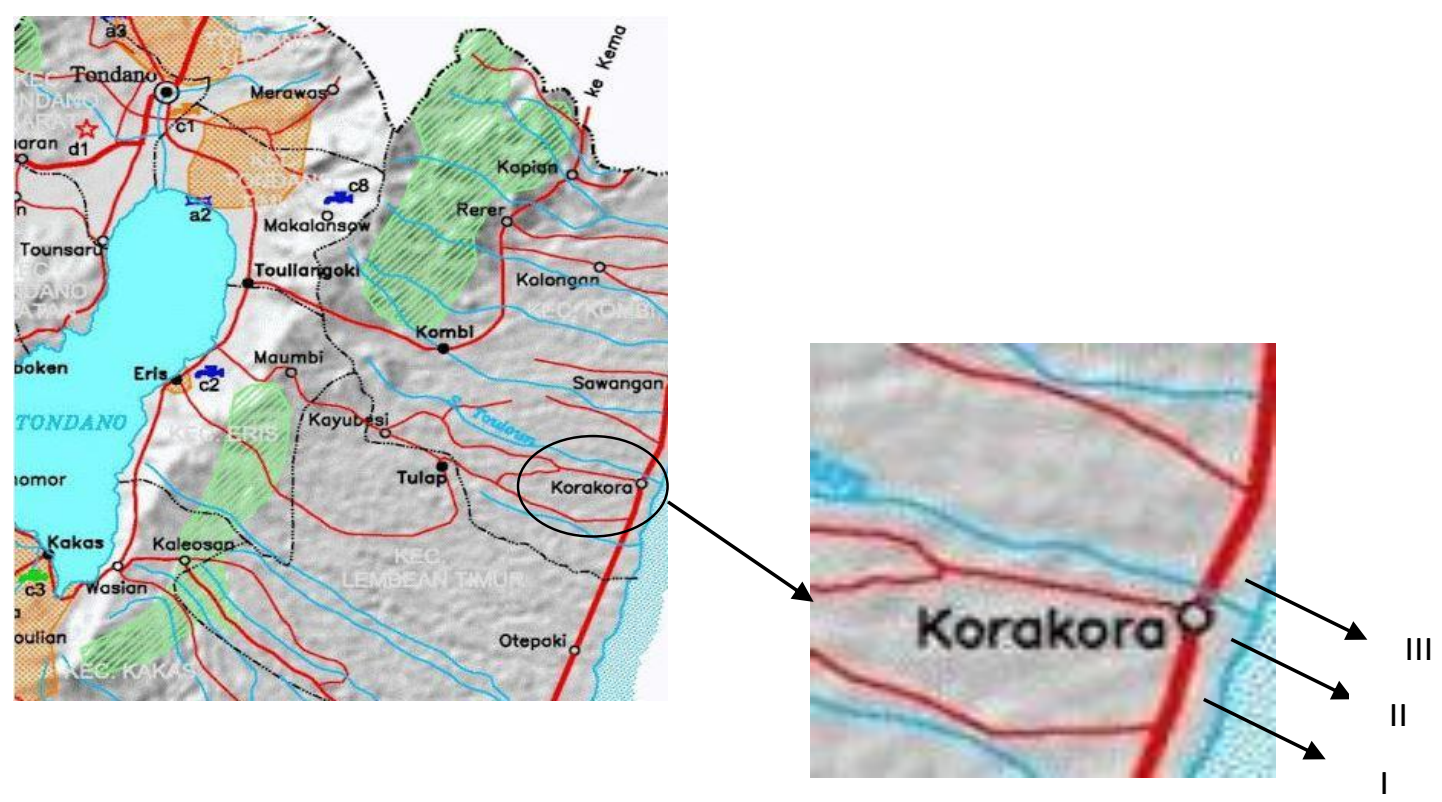

Gambar 1 Stasiun Penelitian I - III (Google Maps, 2017)

\section{HASIL DAN PEMBAHASAN}

\section{Jenis Lamun di Pantai Kora-Kora}

Hasil penelitian diperoleh enam

(6) jenis lamun yang termasuk dalam dua suku yaitu Hydrocharithaceae dan Cymodoceaceae.Suku

Hydrocharithaceae meliputi Enhalus acoroides (Linnaeus f.) Royle, Thalassia hemprichii (Ehrenberg) Ascherson dan Halodule uninervis (Forssk.) Boiss.Suku Cymodoceaceae terdiri ata Cymodocea rotundata (Ehrenberg \& Hemprich) ex Ascherson, Cymodocea serrulata (R. Brown) Aschersondan Syringodium isoetifolium (Ascherson) Dandy (Gambar 2).

Secara umum jenis yang memiliki penyebaran terluas adalah $E$. acoroides dan $S$. isoetifolium, karena dua jenis lamun ini ditemukan pada tiga stasiun penelitian, sedangkan jenis C. serrulata memiliki penyebaran yang terbatas ditemukan pada satu stasiun saja. Meskipun Jenis E, acoroides dan $S$, isoetifolium ditemukan tersebar pada tiga stasiun penelitian, akan tetapi tidak ditemukan merata pada setiap plot di tiga transek yang telah diamati.Adapun jenis lamun yang ditemukan termasuk dalam 14 jenis lamun yang telah teridentifikasi dan tersebar di pesisir tropis indo-pasifik (Short et al. 2007).

Secara visual pada lokasi penelitian khususnya pada stasiun I dan II yang lebih dekat dengan pemukiman serta cenderung tinggi aktivitas manusianya, terdapat hamparan padang lamun yang cukup luas, akan tetapi terlihat banyak lamun yang mati, sedangkan di stasiun III yang jauh dari pemukiman dan jarang aktivitas manusia padang lamun yang ada nampak hijau dan baik. Data yang didapatkan bahwa jenis lamun pada stasiun I dan II berjumlah 4 jenis 
sedangkan di stasiun III ada 5 jenis. Keberadaan lokasi yang jauh dari aktivitas manusia diduga menjadi salah satu faktor pendukung selain faktor lingkungan lainnya, seperti disebutkan dalam Maabuat (2011) bahwa salah satu faktor lamun akan tumbuh dengan baik jika lokasi tempat tumbuhnya lamun jauh dari aktivitas warga. Jenis E. acoroidesmerupakan salah satu lamun yang paling tahan terhadap faktor fisik lingkungan perairan (Susetiono 2004).

\section{Kerapatan Lamun di Pantai Kora- Kora}

Kerapatan individu rata-rata lamun yang tertinggi yaitu Syringodium isoetifolium sebesar 1529 individu/ $\mathrm{m}^{2}$ dan terendah yaitu Cymodocea rotundata sebesar 275 individu/ $\mathrm{m}^{2}$. Stasiun III yang terletak di dekat hutan yang jauh dari aktivitas penduduk dan permukiman memiliki kerapatan total jenis tertinggi, yaitu sebesar 8019 individu $/ \mathrm{m}^{2}$ (5 jenis) dan diikuti oleh Stasiun II, yaitu sebanyak individu $/ \mathrm{m}^{2}$ (4 jenis). Kerapatan total jenis terendah diamati pada Stasiun I yang dekat dengan pemukiman penduduk, yaitu 3936 individu/m².

\section{Indeks Keanekaragaman (H')} Indeks keanekaragaman Shannon-Wienner ( $\mathrm{H}^{\prime}$ ) lamun di Pantai Kora-Kora dapat dilihat pada Gambar 3. Keanekaragaman jenis $\left(\mathrm{H}^{\prime}\right)$ lamun di Stasiun I, II dan III berturut-turut yaitu 1,$37 ; 1,35$ dan 1,45 . Nilai indeks $H^{\prime}$ untuk keseluruhan lokasi penelitian sebesar 1,71. Berdasarkan nilai H' tersebut, keanekaragaman jenis lamun termasuk sedang $\left(1 \leq H^{\prime} \leq 3\right)$. Indeks keanekaragaman jenis lamun tingkat sedang ini juga dapat menunjukkan tingkat stabilitas lamun. Semakin tinggi nilai $H^{\prime}$ maka stabilitas lamun juga semakin baik. Nilai keanekaragaman lamun tingkat sedang ini menunjukkan tingkat stabilitas lamun juga sedang akibat adanya tekanan dari aktivitas manusia dari permukiman.

Keanekaragaman, kelimpahan dan kekayaan lamun pada setiap lokasi berkaitan erat dengan faktor lingkungan. Aktivitas penduduk dapat menurunkan keanekaragaman jenis lamun. Menurut Simamora (2012), semakin tinggi nilai indeks keanekaragaman suatu perairan maka semakin rendah pula tingkat pencemarannya.

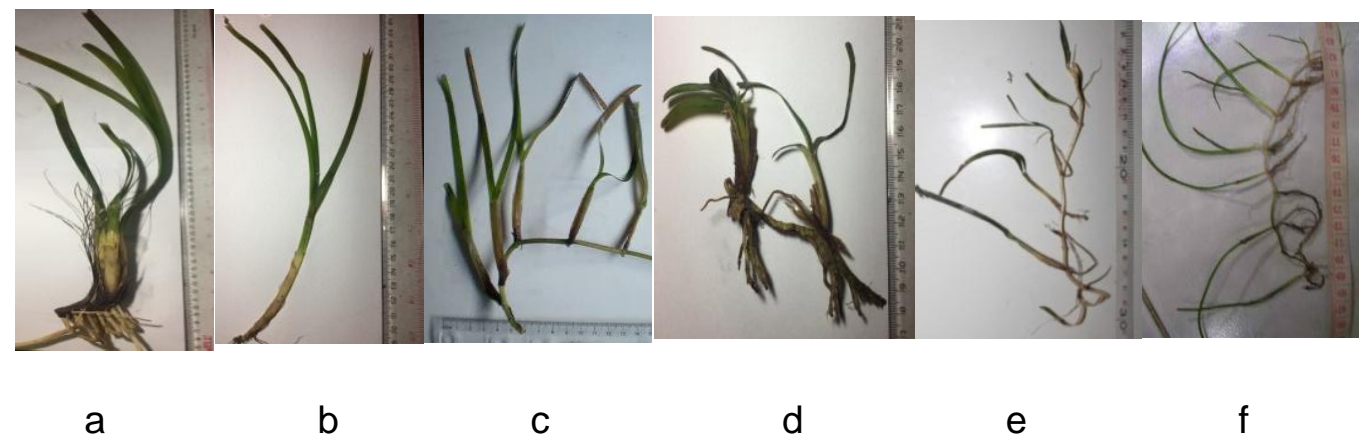

Gambar 2. Jenis Lamun di Lokasi Penelitian

a. Enhalus acoroides, b. Cymodocea rotundata, c. Cymodocea serrulata, d. Thalasia hemprichii, e. Halodule uninervis, f.Syringodium isoetifolium 


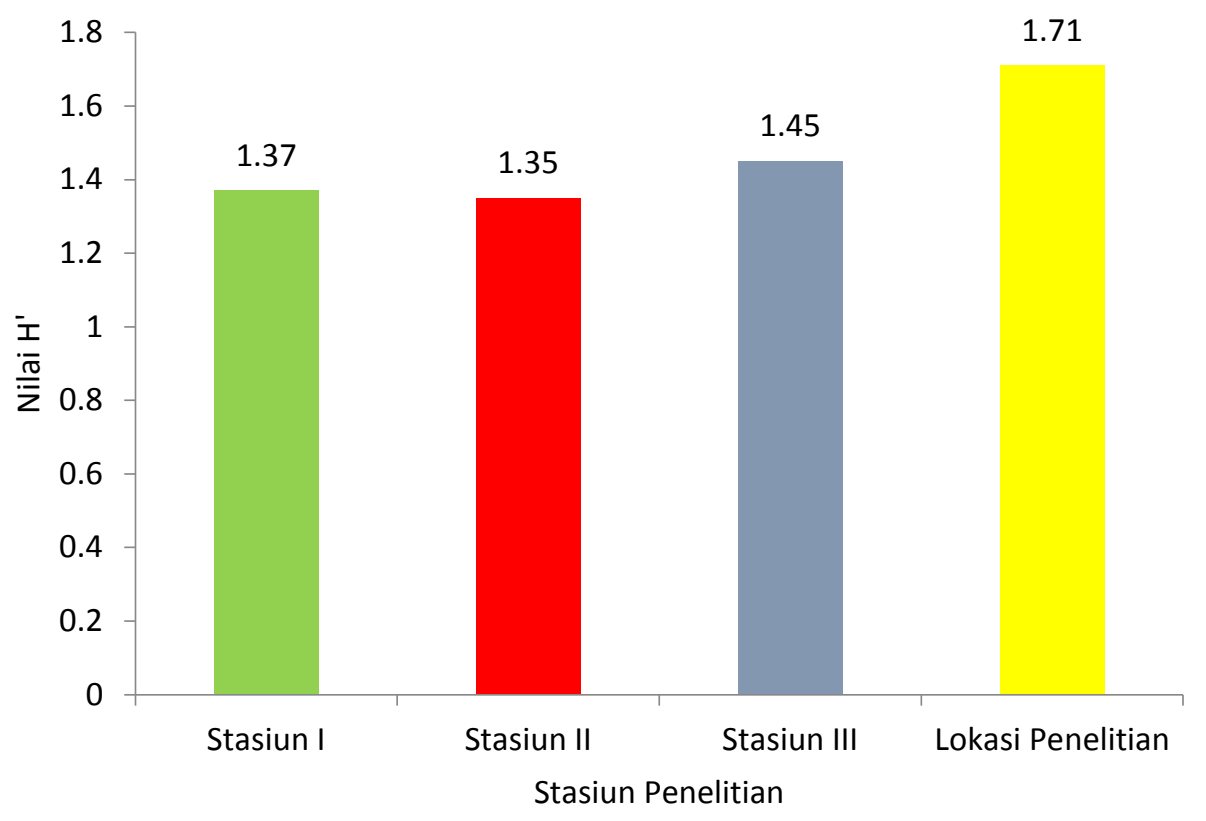

Gambar 3. Indeks Keanekaragaman Jenis Lamun ( $\left.H^{\prime}\right)$

\section{KESIMPULAN}

Sebanyak enam (6) jenis lamun ditemukan di Pantai Kora-Kora yang termasuk dalam dua (2) suku, yaitu Hidrocharitaceae (E.acoroides, $T$. hemprichii, $H$. uninervis) dan Cymodoceaceae (C. rotundata, $C$. serrulata dan $S$. isoetifolium). Jenis yang berperan penting berdasarkan INP di Stasiun I, II dan III berturut-turut ialah $E$. acoroides $(58,50 \%), H$. uninervis $(58,60 \%)$ dan $S$. isoetifolium $(63,0 \%)$. Indeks keanekaragaman jenis lamun di lokasi penelitian di Panta Kora-Kora termasuk sedang dengan nilai H' sebesar 1,71.

\section{DAFTAR PUSTAKA}

Azkab MH (2006) Ada apa dengan lamun. Oseana 31(3): 45-55

Lee K-S, Park SR, Kim YK (2007) Effect of irradiance, temperature, and nutrients on growth dynamics of seagrass: a review. J. Experimental Marine Biology and Ecology 350:144-175
Maabuat PV (2011) Analisis vegetasi lamun (seagrass) di pesisir Pantai Molas, Meras dan Bahowo Kota Manado. Tesis. Universitas Sam Ratulangi. Manado

Magurran AE (1991) Ecological diversity and its measurement. Chapman \& Hall, New York

Nainggolan P (2011) Distribusi spasial dan pengelolaan lamun (seagrass) di Teluk Bakau, Kepulauan Riau. Skripsi. IPB. Bogor

Peuru G (2005) Studi morfologi lamun (seagrass) di pesisir Perairan Semenanjung Minahasa dan sekitarnya. Tesis. Pascasarjana Unsrat. Manado

Putra RP (2015) Struktur komunitas padang lamun di perairan Tanah Merah Desa Penaga Kecamatan Teluk Bintan Kabupaten Bintan Propinsi Kepulauan Riau. Skripsi. Fakultas IImu Kelautan dan Perikanan. Kepulauan Riau 
Short FT, Cole R (2003) Global seagrass research method. Elsevier Science, Amsterdam

Susetiono (2004) Fauna padang lamun Tanjung Merah Selat Lembeh. Pusat Penelitian OseanografiLIPI, Jakarta

Takaendengan K (2007) Kajian ekonomi fauna yang berasosiasi dengan lamun di perairan
Tanjung Merah Bitung Sulut. Tesis. Program Pascasarjana Unsrat

Zakiah S (2015) Keanekaragaman lamun (seagrass) di pesisir Desa Lihunu Pulau Bangka Kecamatan Likupang Kabupaten Minahasa Utara. Skripsi. Universitas Sam Ratulangi. Manado 
